\title{
Subcritical water extraction (SWE) of Zingiber zerumbet using two level full factorial design
}

\author{
Izzati Mohamad Abdul Wahab, Mariam Firdhaus Mad Nordin*, Siti Nur Khairunisa Mohd Amir
}

Shizen Conversion and Separation Technology, Malaysia-Japan International Institute of Technology, Universiti Teknologi Malaysia, Jalan Sultan Yahaya Petra, 54100 Kuala Lumpur, Malaysia

* Corresponding author: mariamfirdhaus@utm.my

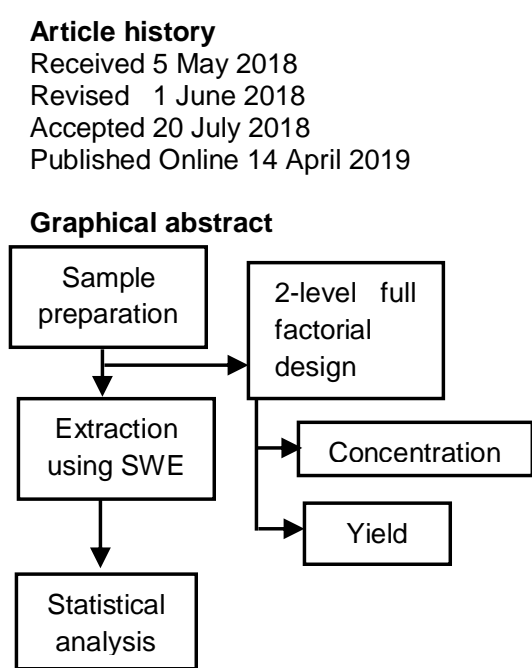

le history

\begin{abstract}
Zingiber zerumbet was reported to has chemo preventive effects and was suggested as one of the therapeutic treatments for cancer. In this study, Z. zerumbet was extracted using subcritical water extraction (SWE) by employing two level full factorial design. $2^{k}$ full factorial design was employed using 18 runs with 10 repeats in central points. The independent variables factors were temperature $\left(100-150^{\circ} \mathrm{C}\right)$, time $(10-30$ minutes) and material ratio $(1: 10$ and 1:20 $\mathrm{g} / \mathrm{ml})$ for the evaluation of highest zerumbone concentration and overall yield of extracted $Z$. zerumbet. Effects of extraction temperature and time were found to be significant on all responses with $p$-value $<0.05$. However, the material ratio only gave significant effect on the zerumbone concentration and less significant on the yield. In addition, the value of curvature was found to be significant, thus indicating the relation between the independent variables and the response was linear. Therefore, it was found that the concentration of zerumbone and yield from $Z$. zerumbet extracted by SWE were significantly affected by temperature and time of extraction.
\end{abstract}

Keywords: Subcritical water extraction, two level factorial design, yield, zerumbone, Zingiber zerumbet

\section{INTRODUCTION}

Natural herbs have received a great attention from researchers around the world due to their medicinal properties. The latest statistic indicates that botanical and medicinal plant is the most widely used product in pharmaceutical area which makes about 30 to 40 percent (Liang \& Fan, 2013). This is due to the incomparable advantages compared to the conventional chemical drug, which including lower toxicity and the availability in ingestive form (Norfazlina et al., 2013). However, among 250,000 of higher plants, only $5-15 \%$ have been explored for their bioactive compound (Amin et al., 2009), indicating that there is a lot of potential yet to be discovered. One of the local herbs in Malaysia which has been used in traditional medicine is Zingiber zerumbet of the Zingiberaceae family.

$Z$. zerumbet from the Zingiberaceae family has received a lot of attention from researchers around the world since decades. $Z$. zerumbet is also known as shampoo ginger and traditionally known as lempoyang in Malaysia. It is believed to originate from India (Baby et al., 2009) but has been widely cultivated in tropical and subtropical climate countries around the world (Zakaria et al., 2011). Z. zerumbet has been widely investigated due to the extensive medicinal properties that it possesses. These include anti-bacterial (Azelan et al., 2015), anti-mutagenic (Kumar et al., 2013), anti-inflammatory (Moektiwardoyo et al., 2016), anti-allergic (Zakaria et al., 2010), antimicrobial (Kader et al., 2011) and anti-hypersensitive (Chaung et al., 2008). The most significant medicinal properties that it has is anticancer properties.
Z. zerumbet extract has shown significant effect both in vitro and in-vivo analyses for cancer-related diseases. Examples of cancer cases which shows anti-cancer properties of $Z$. zerumbet are breast (Rumiza \& Pihie, 2005), liver (Sakinah et al., 2007), leukemia (Norfazlina et al., 2013), colon (Yodkeeree et al., 2009) and cervix cancer (Abdul et al., 2008). It is identified that the major bioactive compound which is responsible for being the chemo preventive agent is zerumbone which is the major constituent of $Z$. zerumbet and makes up about 68.9 to $84.8 \%$ of the rhizome oils based on the geographical location (Baby et $a l ., 2009)$. However, it is relatively difficult to extract the targeted bioactive compound from plants due to the complex chemical composition of the lead compound in medicinal plants (Liang \& Fan, 2013). Extraction is a crucial step for the isolation and recovery of bioactive compound from plants. However, almost all of the reported extraction methods of $Z$. zerumbet are involved the conventional methods which use organic solvent and have longer extraction time (Joana Gil-Chávez et al., 2013). Unlike the conventional method, subcritical water extraction is not only environmental friendly but also has shorter extraction time (Plaza \& Turner, 2015).

Subcritical water extraction takes the advantage of the unique properties of water when high temperature and pressure are applied. Subcritical region is shown in Figure 1 with temperature between 100 to $374^{\circ} \mathrm{C}$ and pressure varied from 10 to 80 bar (enough to maintain the water in liquid form) (Teo et al., 2010). At subcritical water condition, the dielectric constant of water is altered. This alteration causes the decrease in its dielectric constant in order to match with the common organic solvent. For example, at ambient temperature, water 
has dielectric constant close to 80. However, under subcritical condition, the dielectric constant can be reduced up to 27 at temperature of $250^{\circ} \mathrm{C}$ (Herrero et al., 2006). This dielectric constant matches that of the commonly used organic solvent which is ethanol (Miller \& Hawthorne, 2000).

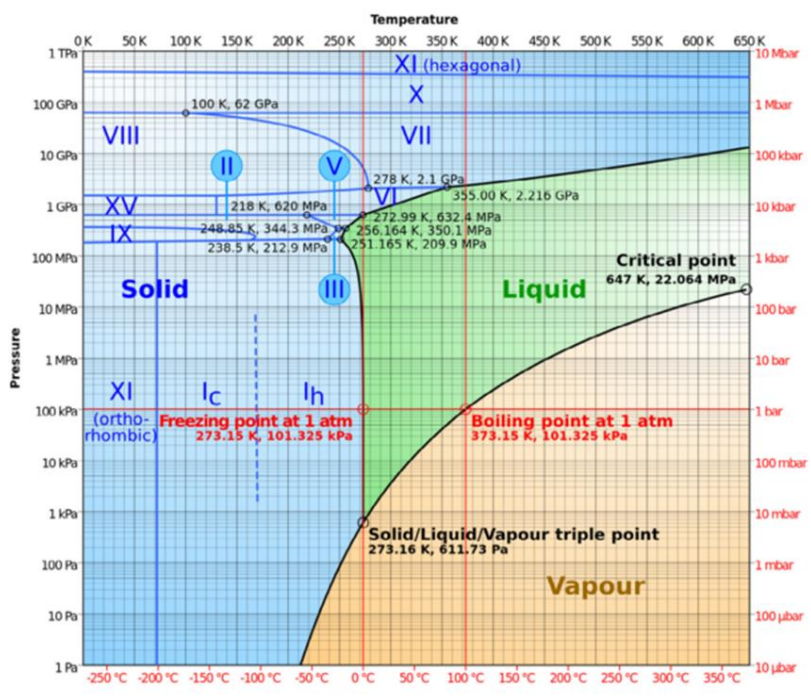

Fig. 1 Phase diagram of water (Plaza \& Turner, 2015).

Even so, the extraction method depends mostly on the extraction parameters such as temperature, time, power, ratio and so on. The most widely used method is one-factor-at-a-time (OFAT). Although most of the times, this method is found to be very significant, it has several drawbacks such as expensive (due to the excessive use of raw material), time consuming and does not include interaction parameters which may cause inaccuracy (Frey et al., 2003).

In order to eliminate the drawbacks of OFAT, two level full factorial design is employed as the statistical screening process. This approach has been found to be useful in evaluating the main and interaction effects with minimum experimental runs. Therefore, the aim of this study was to screen the independent factors namely, temperature $\left(100\right.$ to $\left.150^{\circ} \mathrm{C}\right)$, extraction time (10 to 30 minutes) and material ratio $(1: 10$ and $1: 20 \mathrm{~g} / \mathrm{ml})$. The independent variable would be investigated on the effect on the following responses; concentration $(\mathrm{mg} / \mathrm{g})$ and yield of Z.zerumbet $(\%)$ with the aim in getting the highest response value. To our knowledge, no study has been conducted in finding the range for subcritical water extraction for Z.zerumbet using two level full factorial design.

\section{EXPERIMENTAL}

\section{Plant material and sample preparation}

Z. zerumbet was procured from local farm in Bentong, Pahang, Malaysia. The rhizomes were cleaned and inspected to remove any damaged or infested rhizomes. The rhizomes were sliced into small pieces approximately of $2 \mathrm{~mm}$ cross-section. The sliced rhizomes were dried in an air-forced convection oven at $50^{\circ} \mathrm{C}$ until the moisture content would reach an average of 8 to $10 \%$. The dried rhizomes were grounded into powder and sieved accordingly. The mean particle size (MPS) was in the range of $2.86 \mathrm{~mm}$ to $0.89 \mathrm{~mm}$. All samples were kept in sealed bag at room temperature prior to extraction.

\section{Chemicals}

Zerumbone standard (purity > 99\%) was purchased from Chromodex Inc (CA, USA). Methanol and acetronitrile used were of HPLC grade (Merck, Germany). Nitrogen gas with purity of $>99.9 \%$ was purchased from Linde (Malaysia).

\section{Extraction}

The extraction was carried out using the subcrititcal water extraction (SWE) CLEAR prototype (UTM, KL) with $1000 \mathrm{ml}$ of two high pressure vessels which were extraction cell and cooling vessel. The extraction pressure was regulated by adjusting the pressure regulator. Nitrogen gas $(99.9 \%)$ was used to purge out the air from the vessel and to transfer the extractant to the cooling vessel. The temperature was set at the control panel before performing each extraction process. The time for the extraction process was taken once the desired temperature was achieved using a stopwatch. The extraction was performed under various experimental conditions in accordance with the two level full factorial design to determine the best SWE operating condition for Z. zerumbet.

\section{Yield calculation}

In order to obtain oleoresin from SWE, the extractant would be subjected to freeze-dryer to remove the solvent. The oleoresin was first kept in a freezer at a temperature of $-80^{\circ} \mathrm{C}$ before undergoing into freeze-dryer. The process was conducted for 2-3 days until dried powder was obtained. The powder was kept in an amber vial at room temperature prior to analysis. The percentage of yield was calculated using the equation:

Yield $(\%)=\frac{\mathrm{W}_{\mathrm{f}}(\mathrm{g})-\mathrm{W}_{\mathrm{i}}(\mathrm{g})}{\text { Sample matrix }(\mathrm{g})} \times 100$

Where; $\mathrm{w}_{\mathrm{f}}=$ Weight of final beaker with $Z$. zerumbet; $\mathrm{w}_{\mathrm{i}}=$ Initial weight of empty beaker

\section{High Performance Liquid Chromatography (HPLC)}

The analytical High Performance Liquid Chromatography (HPLC) in this experiment was conducted using Waters apparatus (2487 Dual $\lambda$ Absorbance and 2690 Separation Module). The system was equipped with PDA detector and the signals were processed with Empower $^{\mathrm{TM}}$ software (Origin). The analytical column used was $\mathrm{C} 18$ (Symmetry XX). The method was slightly modified from previous work (Eid et al., 2010). The mobile phase for zerumbone was composed of $100 \%$ methanol (solvent A) and $100 \%$ acetonitrile (solvent B). The mobile phases were prepared daily and filtered using $0.45 \mu \mathrm{m}$ membrane and sonicated prior to use. The total running time for zerumbone was 5 minutes and the separation was carried out in isocratic elution with $35 \%$ and $65 \%$ of solvent A and B, respectively. The elute was monitered by PDA detector at a flow of $1 \mathrm{ml} / \mathrm{min}$ at the wavelength of $254 \mathrm{~nm}$.

\section{Concentration calculation}

The standard calibration curve was constructed by preparing a total of 6 different concentrations which were $5 \mathrm{ppm}, 10 \mathrm{ppm}, 20$ ppm, $50 \mathrm{ppm}, 100 \mathrm{ppm}$ and $500 \mathrm{ppm}$. Dilution was made by diluting the standard with methanol. The absorbance was plotted against the concentration to obtain the equation of a straight line. The concentration of the sample was calculated using the equation below:

Concentration $(\mathrm{mg} / \mathrm{g})=\frac{\text { Concentration }(\mu \mathrm{g} / \mathrm{ml}) \times F V(\mathrm{ml}) \times D F}{\text { Weight of sample matrix }(\mathrm{g})} \div 1000$

Where; FV = Final volume of solvent and DF= Dilution factor

\section{Experimental design and statistical analysis}

Two level full factorial design was used to screen the independent variable and the range for the operating condition. The independent variables were tabulated in Table 1.

Table 1 Independent variables and their levels for two leve fulll factorial design.

\begin{tabular}{llll}
\hline & Notation & Levels & \\
\hline Independent variables & & -1 & 1 \\
Temperature $\left({ }^{\circ} \mathbf{C}\right)$ & $\mathrm{A}$ & 100 & 150 \\
Time (min) & $\mathrm{B}$ & 10 & 30 \\
$\begin{array}{l}\text { Material ratio (dry raw material: } \\
\text { subcritical water, g:ml) }\end{array}$ & $\mathrm{C}$ & $1: 10$ & $1: 20$ \\
\hline
\end{tabular}


The independent variable was investigated based on the following responses; concentration and yield of $Z$. zerumbet. The resulting values and statistical analysis were processed using Design Expert Verison 7.1.6 and ANOVA was used to determine the statistical significance of the model. The experimental design was included five replications at center point. However, since the material ratio was a categoric factor, the center point would be duplicated at both low and high levels, thus producing 10 center points instead of five. Therefore, total of 18 runs were carried out in randomized order and shown in Table 2. The replication at center point was executed to allow the estimation of pure error and to detect curvature in the model.

Table 2 Experimental runs in randomized order.

\begin{tabular}{lllll}
\multicolumn{2}{l}{ Experiment } & \multicolumn{3}{l}{$\begin{array}{l}\text { Independent } \\
\text { variables }\end{array}$} \\
\hline $\begin{array}{l}\text { Std. } \\
\text { order }\end{array}$ & $\begin{array}{l}\text { Run } \\
\text { order }\end{array}$ & $\mathbf{A}$ & $\mathbf{B}$ & $\mathbf{C}$ \\
$\mathbf{8}$ & 1 & 150 & 30 & $1: 20$ \\
$\mathbf{1 7}$ & 2 & 125 & 20 & $1: 10$ \\
$\mathbf{7}$ & 3 & 100 & 30 & $1: 20$ \\
$\mathbf{1}$ & 4 & 100 & 10 & $1: 10$ \\
$\mathbf{3}$ & 5 & 100 & 30 & $1: 10$ \\
$\mathbf{1 4}$ & 6 & 125 & 20 & $1: 20$ \\
$\mathbf{1 2}$ & 7 & 125 & 20 & $1: 20$ \\
$\mathbf{1 6}$ & 8 & 125 & 20 & $1: 20$ \\
$\mathbf{1 0}$ & 9 & 125 & 20 & $1: 20$ \\
$\mathbf{1 8}$ & 10 & 125 & 20 & $1: 20$ \\
$\mathbf{2}$ & 11 & 150 & 10 & $1: 10$ \\
$\mathbf{4}$ & 12 & 150 & 30 & $1: 10$ \\
$\mathbf{9}$ & 13 & 125 & 20 & $1: 10$ \\
$\mathbf{6}$ & 14 & 150 & 10 & $1: 20$ \\
$\mathbf{1 5}$ & 15 & 125 & 20 & $1: 10$ \\
$\mathbf{5}$ & 16 & 100 & 10 & $1: 20$ \\
$\mathbf{1 3}$ & 17 & 125 & 20 & $1: 10$ \\
$\mathbf{1 1}$ & 18 & 125 & 20 & $1: 10$ \\
\hline
\end{tabular}

\section{RESULTS AND DISCUSSION}

\section{High Performance Liquid Chromatography (HPLC)}

Zerumbone; the known major constituent found in Z. zerumbet was measured in term of concentration. Standard calibration curve using zerumbone standard was constructed as shown in Figure 2. From the graph, the correlation between absorption of zerumbone, $(\mathrm{AU})$ and zerumbone concentration, (ppm) was linear. The equation of the straight line is was $\mathrm{Y}=13152 \mathrm{X}+125087$ with $\mathrm{R}^{2}$ value of $99.7 \%$. According to Snyder et al., (2012), the $\mathrm{R}^{2}$ of the linearity for the standard calibration curve should be higher than $99.5 \%$. Therefore the obtained $\mathrm{R}^{2}$ in this study was found to be acceptable.

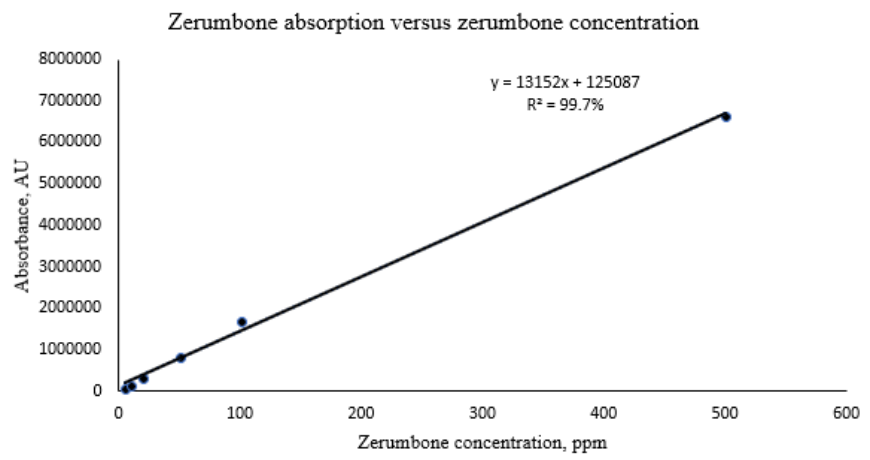

Fig. 2 Standard calibration curve of zerumbone.

\section{Range determination of the extraction variables}

The experimental range of each of the extraction variable was determined based on several condition such as degradation and the limitation of the extraction machine. For temperature, the range chosen was between $100^{\circ} \mathrm{C}$ to $150^{\circ} \mathrm{C}$. The minimum temperature was chosen based on the minimum condition required to apply the subcritical water extraction. In addition, several studies have reported that Z. zerumbet was the polar compound (Hasham @ Hisam et al., 2003), which favoring the extraction at low temperature. For the upper limit, $150^{\circ} \mathrm{C}$ was chosen based on the previous research reported that most of essential oil extractions from natural plant by SWE have the optimum temperature of $150^{\circ} \mathrm{C}$ (Liang \& Fan, 2013). The time chosen was in the range of 10 to 30 minutes and based on the previous literature study (Plaza \& Turner, 2015). For solid to solvent ratio, 1:10 and 1:20 were chosen based on the findings from (Awang et al., 2014) which stated that the ratio above 1:20 was not necessary as the extraction yield was limited due to the inavailability of total available solute when excessive solvent was used.

\section{Influence of extraction parameters on concentration and yield}

In general, all the response models were found to be significant whereby the p-value of the model was less than 0.05 as shown in Table 4. It could also be observed that an increase in temperature would cause an increase in the concentration and yield. In contrary, the increase in time could only cause an increment in the yield but only a slight effect was observed on the concentration. Ratio has significant effect on the concentration but not on the yield.

Table 3 Responses of the dependent variables on the extraction conditions.

\begin{tabular}{lllllll}
\hline Experiment & \multicolumn{3}{l}{$\begin{array}{l}\text { Independent } \\
\text { variables }\end{array}$} & & Responses & \\
\hline $\begin{array}{l}\text { Std. } \\
\text { order }\end{array}$ & $\begin{array}{l}\text { Run } \\
\text { order }\end{array}$ & $\mathbf{A}$ & $\mathbf{B}$ & $\mathbf{C}$ & $\begin{array}{l}\text { Concentration } \\
\text { (mg/g) }\end{array}$ & $\begin{array}{l}\text { Yield } \\
(\%)\end{array}$ \\
$\mathbf{8}$ & 1 & 150 & 30 & $1: 20$ & 9.39 & 17.52 \\
$\mathbf{1 7}$ & 2 & 125 & 20 & $1: 10$ & 4.73 & 13.56 \\
$\mathbf{7}$ & 3 & 100 & 30 & $1: 20$ & 3.13 & 11.25 \\
$\mathbf{1}$ & 4 & 100 & 10 & $1: 10$ & 1.93 & 9.68 \\
$\mathbf{3}$ & 5 & 100 & 30 & $1: 10$ & 1.98 & 12.38 \\
$\mathbf{1 4}$ & 6 & 125 & 20 & $1: 20$ & 8.30 & 11.87 \\
$\mathbf{1 2}$ & 7 & 125 & 20 & $1: 20$ & 8.15 & 10.95 \\
$\mathbf{1 6}$ & 8 & 125 & 20 & $1: 20$ & 8.52 & 9.89 \\
$\mathbf{1 0}$ & 9 & 125 & 20 & $1: 20$ & 8.42 & 11.46 \\
$\mathbf{1 8}$ & 10 & 125 & 20 & $1: 20$ & 8.27 & 10.84 \\
$\mathbf{2}$ & 11 & 150 & 10 & $1: 10$ & 5.38 & 11.78 \\
$\mathbf{4}$ & 12 & 150 & 30 & $1: 10$ & 6.73 & 20.18 \\
$\mathbf{9}$ & 13 & 125 & 20 & $1: 10$ & 4.66 & 11.23 \\
$\mathbf{6}$ & 14 & 150 & 10 & $1: 20$ & 8.75 & 15.04 \\
$\mathbf{1 5}$ & 15 & 125 & 20 & $1: 10$ & 4.74 & 13.61 \\
$\mathbf{5}$ & 16 & 100 & 10 & $1: 20$ & 6.39 & 9.12 \\
$\mathbf{1 3}$ & 17 & 125 & 20 & $1: 10$ & 4.59 & 12.89 \\
$\mathbf{1 1}$ & 18 & 125 & 20 & $1: 10$ & 4.51 & 12.96 \\
\hline
\end{tabular}

Table 4 P-values of respective factors and models.

\begin{tabular}{|c|c|c|c|c|c|}
\hline \multirow[t]{2}{*}{ Response } & \multicolumn{4}{|c|}{ P-value for responses } & \multirow[t]{2}{*}{ R-squared } \\
\hline & Model & A & B & C & \\
\hline $\begin{array}{l}\text { Concentration } \\
\text { Yield }\end{array}$ & $\begin{array}{l}<0.0001 \\
0.0001\end{array}$ & $\begin{array}{l}<0.0001 \\
<0.0001\end{array}$ & $\begin{array}{l}0.0076 \\
0.0002\end{array}$ & $\begin{array}{l}<0.0001 \\
0.6668\end{array}$ & $\begin{array}{l}99.87 \\
94.95\end{array}$ \\
\hline
\end{tabular}

Table 5 Percentage contribution of the extraction variables on response.

\begin{tabular}{lll}
\hline Factor & \multicolumn{2}{l}{ Percentage contribution $(\%)$} \\
\hline & Concentration $(\mathrm{mg} / \mathrm{g})$ & Yield $(\%)$ \\
\hline A & 36.25 & 46.99 \\
B & 0.19 & 23.77 \\
C & 17.36 & 0.11 \\
AB & 3.47 & 3.52 \\
AC & 0.023 & 0.50 \\
BC & 2.07 & 4.06 \\
ABC & 0.87 & 2.76 \\
Curvature & 39.65 & 13.70 \\
\hline
\end{tabular}




\section{Influence of temperature on concentration and yield}

On the basis of each parameter, temperature has the most influence on the response. This was in agreement with what has been found by several studies which indicated that temperature was one of the main factors that contributed to the increase in the extraction efficiency (Liang \& Fan, 2013). From the perturbation plot, a great slope was shown in both the concentration and yield by factor A (temperature). In diagram $\mathrm{B}$, it could be observed that at increased temperature, the concentration was increased from 3.78 to $7.53 \mathrm{mg} / \mathrm{g}$. In term of yield, the temperature showed significant effect whereby the yield was increased from 11 to $15 \%$ when the temperature was increased. This condition could be elucidated by the subcritical water extraction mechanism. As the temperature was increased, the dielectric constant of water was decreased and mimicked the polarity of organic solvent with lower polarity. Following the "like dissolve like" principle, as the polarity of water was decreased, it was enabled to dissolve more less polar compound which caused the concentration of zerumbone to increase. In contrast with what has been reported previously which stated that zerumbone was a polar compound (Hasham@ Hisam et al., 2003), this study suggested otherwise. Such discrepancy might be due to the different method of extraction and cultivation (Nag et al., 2013). However, further increase in temperature was not recommended due to other reaction which might occur in SWE when the natural bioactive compound was dissolved in hot liquid water. This including Maillard reaction, thermoxidaton and caramelization such as demonstrated by (Plaza et al., 2010).

\section{Influence of time on concentration and yield}

For time effect, the most significant effect it has was on the total yield. From the perturbation plot, factor A has slightly higher significant effect on the yield compared to B. It was observed that the highest yield was obtained when the extraction was maximum which was at 30 minutes. This could be elucidated by the increase in mass transfer rate due to the prolonged extraction time which enabled the diffusion of the bioactive compound into the bulk liquid (Sarip et al., 2014). Shorter extraction time did not give enough time for the bioactive compound to travel from the solid matrix and into the bulk liquid. However, prolonged extraction time was not recommended since in several studies related to SWE on natural plant, the increase in extraction time could cause over heat supplied which would effect the volatile oil presented in the essential oil component by drying it up (Silva et al., 2007). The extraction mechanism of a typical solute extract in typical solvent was shown in Fig. 3.

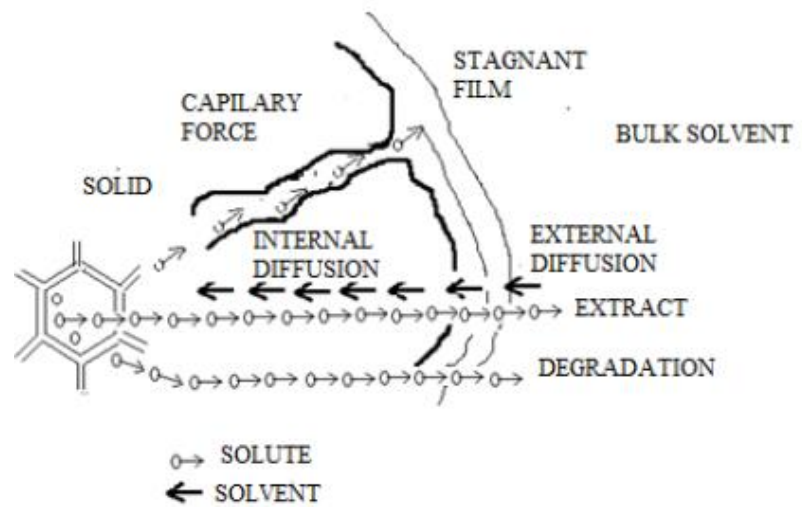

Fig. 3 Extraction mechanism of typical solute to solvent (Azian et al., 2014).

Fig. 3 shows the movement of the extract out of the capilary wall of the plant when the process was occurred. The difference in concentration between the solvent and the concentration inside the capilary wall of the plant would enable the transfer of the extract from inside the wall to the solvent via diffusion.

\section{Influence of ratio on concentration and yield}

In term of the ratio effects, the slope in C, D and $\mathrm{H}$ of Fig. 4 showed significant effect on the responses that indicated by the steep slope. However, the effect of ratio in $\mathrm{G}$ showed a slight interaction with temperature on the yield. In term of which ratio would show greater effect on the response, ratio of 1:20 in D indicated that the extraction efficiency was higher compared to 1:10 ratio. It could be seen that the zerumbone concentration was increased with increasing of solid to solvent ratio. This situation could be due to the total solute that exceeded the available solvent.

In SWE, the extraction was depended on the total available surface of the solute. When the solvent was not enough, some of the solutes would not be extracted well. This was due to the rupture of cell wall that would cause the solvent to penetrate the cell and extract the solute into the bulk solvent. Previous study conducted by (Awang et al., 2014) indicated that the highest extraction yield was obtained at ratio of 1:20. The increase in the ratio of solid to solvent showed a steady decline in the extraction yield. Silva et al. (2007) reported that the increase of ratio above 1:20 could limit the extraction yield as excessive solvent was used. In addition, the use of excessive solvent would lead to the increase in the energy consumption and consequently the increase in the cost (Garau et al., 2006).

In term of SWE mechanism, nitrogen gas was used to transfer the extractant from the extraction vessel to the collector vessel. When there was less solvent used, the extraction process delivery was harder due to the lack in medium of transportation. Besides that, the total bioactive compound presented in the natural herb was not completely extracted due to the lack in solvent as the medium of extraction. Therefore, the optimum value for ratio of solid to solvent was important to maximize the extraction efficiency.

The contribution of each of the extraction parameter was shown in Table 5. For both of the responses, temperature was found to be the most influential factor. Interaction effects could also be observed from both of the responses. Both of the models have significant curvature effect $(\mathrm{p}<0.05)$ which showed that the relation between the response and factor was linear. The linearity in two level full factorial design was very important to validate the relation between the factor and the response.

To investigate the interactive effects of the independent variables and their interaction on zerumbone concentration and yield, 3D response surface plots were plotted in Fig. 5 and 6. The ratio shown in this diagram was taken to be the average since ratio has been categorized as categorical when designing the two level full factorial design. In addition, a slight difference was observed when using the actual value of ratio when examining the interaction between the other two independent variables.

For Fig. 5 which was the interaction between temperature, time and the concentration, it could be clearly seen that the concentration was reached its maximum when maximum temperature and time were used. The lowest concentration was $2.5 \mathrm{mg} / \mathrm{g}$ whereas the highest was $8.1 \mathrm{mg} / \mathrm{g}$. Therefore, it could be concluded that the relation between independent variables and the response was linear. This was in agreement with the value of curvature which was found to be significant in the effect list.

For Fig. 6, the 3D plot showed the interaction between temperature and time towards the yield. From the figure, it could be seen that the highest yield obtained was $16.1 \%$ whereas the lowest was $9.8 \%$. These values were achieved at the maximum temperature and time. Therefore, it could be concluded that the relation of independent variables and the response was also found to be linear to that the value of the response was increased as the magnitude of the factors was increased. The curvature for yield model was also found to be significant which supported the relation shown in the $3 \mathrm{D}$ plot.

\section{Optimization of the significant operating parameters}

From the results obtained, the model was optimized by using Design Expert Software version 7.1.6. The model was optimized as such the response was set to be at the maximum value. The selection of which solution to be used should depend on the value of the desirability. A high desirability (approaching 1) indicated that the solution with the proposed operating condition. Fig. 7 shows the contour effect of the proposed operating condition with the desirability. 

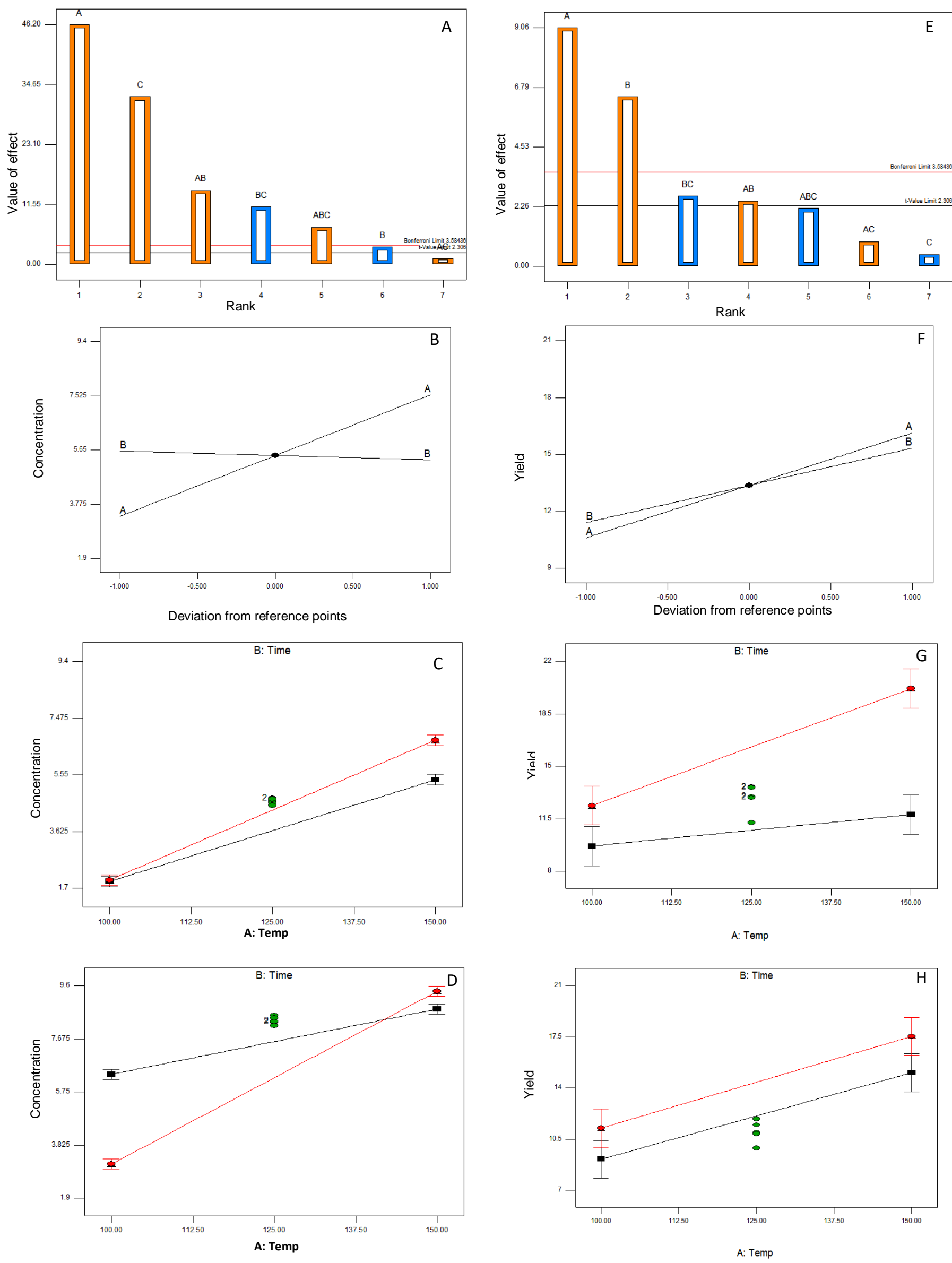

Fig. 4 The Pareto chart ( $A$ and $E$ ) for concentration and yield respectively. The perturbation plot for temperature and time interaction (B) on concentration at average ratio, the interaction effect of temperature, time and ratio of 1:10 and 1:20 on concentration (C and D). The perturbation plot for temperature and time interaction $(F)$ on yield at average ratio, the interaction effect of temperature, time and ratio of $1: 10$ 


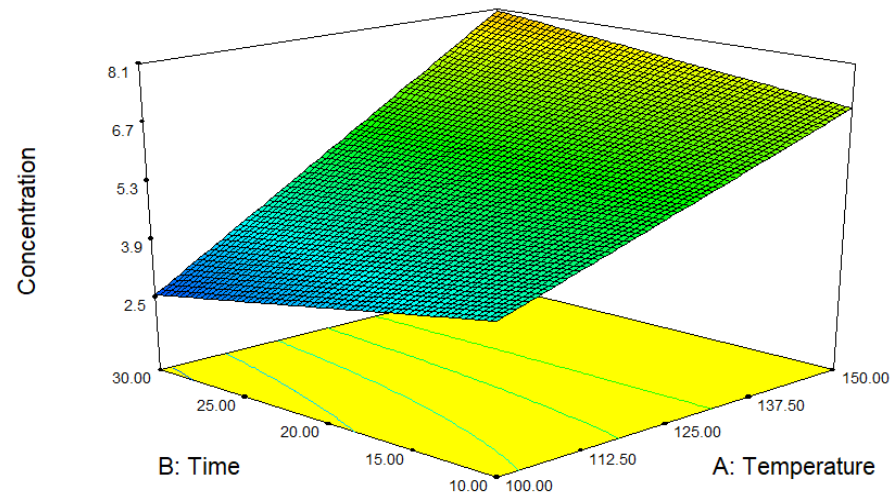

Fig. 5 3D surface plot showing the combine effect of temperature and extraction time at average solid to solvent ratio on the concentration.

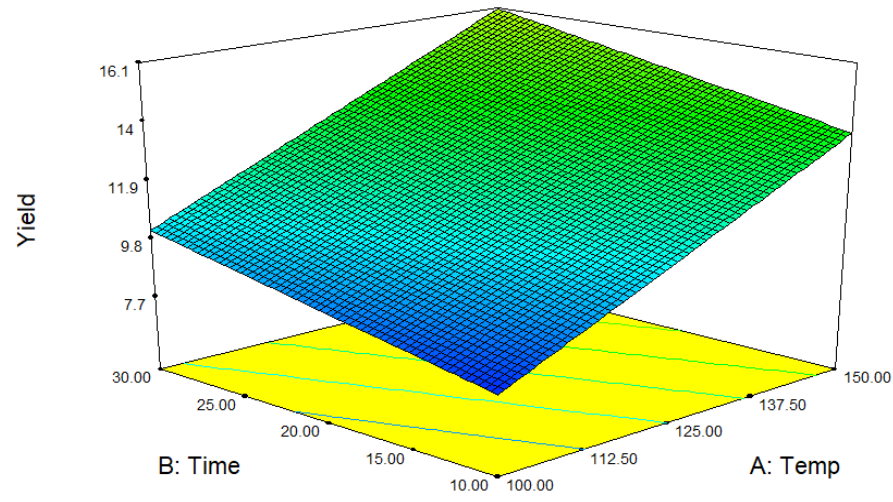

Fig. 6 3D surface plot showing the combine effect of temperature and extraction time at average solid to solvent ratio on the yield.

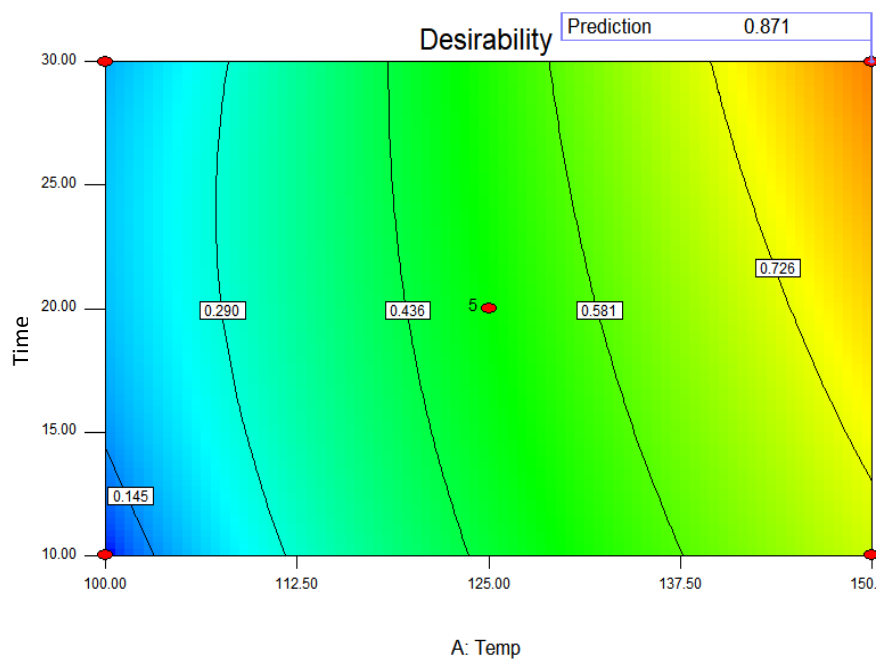

Fig. 7 The proposed solution for optimization

\section{CONCLUSION}

Two level full factorial design with centre point was used as screening for the extraction parameters which include temperature, time and solid to solvent ratio in obtaining higher concentration of zerumbone and yield from the $Z$. zerumbet plant. The obtained result showed that temperature, time and solid to solvent ratio were found to be significant $(\mathrm{p}<0.05)$ in attaining higher concentration whereas for yield, only temperature and time were significant. In addition, the significant value of curvature indicated that the relation between the response and factor was linear, hence validated the screening process. Further optimization by employing the significant factors need to be studied in the future.

\section{ACKNOWLEDGEMENT}

This research was fully funded by a grant from FRGS, 4F782 and PRGS, 4L676 by MOE, Malaysia and Malaysia-Japan International Institute of Technology (MJIIT), Universiti Teknologi Malaysia.

\section{REFERENCES}

Abdul, A. B., Al-Zubairi, A., Tailan, N., Wahab, S. I., Zain, Z. N., Ruslay, S., \& Syam, M. (2008). Anticancer activity of natural compound (Zerumbone) extracted from Zingiber zerumbet in human HeLa cervical cancer cells. International Journal of Pharmacology, 4(3), 160-168.

Amin, A., Gali-Muhtasib, H., Ocker, M., \& Schneider-Stock, R. (2009). Overview of major classes of plant-derived anticancer drugs. International Journal of Biomedical Science, 5(1), 1-11.

Awang, M. A., Azelan, N. A., Ain, N., Wan, A., Aziz, A., Hasham, R., ... Bharu, J. (2014). Influence of processing parameters on the yield and 6gingerol content of Zingiber officinale extract. Journal of Chemical and Pharmaceutical Research, 6(11), 358-363.

Azelan, N. A., Hasham, R., Awang, M. A., Abd Malek, R., Musa, N. F., \& Aziz, R. (2015). Antibacterial activity Zingiber officinale and Zingiber zerumbet essential oils extracted by using turbo extractor. Jurnal Teknologi, 3, 43-47.

Azian, M. N., Anisa, A. N. I., \& Iwai, Y. (2014). Mechanisms of ginger bioactive compounds extract using soxhlet and accelerated water extraction. International Journal of Chemical, Materials Science and Engineering, 8(5), 438-442.

Baby, S., Dan, M., Thaha, A. R. M., Johnson, A. J., Kurup, R., Balakrishnapillai, P., \& Lim, C. K. (2009). High content of zerumbone in volatile oils of Zingiber zerumbet from southern India and Malaysia. Flavour and Fragrance Journal, 2, 301-308.

Chaung, H.-C., Ho, C.-T., \& Huang, T.-C. (2008). Anti-hypersensitive and anti-inflammatory activities of water extract of Zingiber zerumbet (L.) Smith. Food and Agricultural Immunology, 19(2), 117-129.

Eid, E. E. M., Abdul, A. B., Al-zubairi, A. S., \& Aspollah, M. (2010). Validated high performance liquid chromatographic (HPLC) method for analysis of zerumbone in plasma. African Journal of Biotechnology, 9(8), 1260-1265.

Frey, D. D., Engelhardt, F., \& Greitzer, E. M. (2003). A role for "one-factorat-a-time" experimentation in parameter design. Research in Engineering Design, 14 (2), 65-74.

Garau, M. C., Simal, S., Femenia, A., \& Rosselló, C. (2006). Drying of orange skin: Drying kinetics modelling and functional properties. Journal of Food Engineering, 75(2), 288-295.

Hasham @ Hisam, R., Sulaiman, N., Sarmidi, M. R., Aziz, R. A., \& Che Pa, N. F. (2003). Extraction of oleoresin from Zingiber Zerumbet rhizome: Comparative study on yield, zerumbone and curcumin content. Proceedings of International Conference on Chemical and Bioprocess Engineering, 1176-1179.

Herrero, M., Cifuentes, A., \& Iban, E. (2006). Sub- and supercritical fluid extraction of functional ingredients from different natural sources: Plants, food-by-products, algae and microalgae A review. Food Chemistry, 98, 136-148.

Joana Gil-Chávez, G., Villa, J. A., Fernando Ayala-Zavala, J., Basilio Heredia, J., Sepulveda, D., Yahia, E. M., \& González-Aguilar, G. A. (2013). Technologies for extraction and production of bioactive compounds to be used as nutraceuticals and food ingredients: An overview. Comprehensive Reviews in Food Science and Food Safety, 12(1), 5-23.

Kader, G., Nikkon, F., Rashid, M. A., \& Yeasmin, T. (2011). Antimicrobial activities of the rhizome extract of Zingiber zerumbet Linn. Asian Pacific Journal of Tropical Biomedicine, 1(5), 409-412.

Kumar, S. C. S., Srinivas, P., Negi, P. S., \& Bettadaiah, B. K. (2013). Antibacterial and antimutagenic activities of novel zerumbone analogues. Food Chemistry, 141(2), 1097-1103.

Liang, X., \& Fan, Q. (2013). Application of sub-critical water extraction in pharmaceutical industry. Journal of Materials Science and Chemical Engineering, 01(05), 1-6.

Miller, D. J., \& Hawthorne, S. B. (2000). Solubility of liquid organics of environmental interest in subcritical (hot/liquid) water from $298 \mathrm{~K}$ to 473K. Journal of Chemical and Engineering Data, 45, 315-318.

Moektiwardoyo, M., Naspiah, N., \& Iskandar, Y. (2016). Antiinflammatory activity of decoction of Lia berueng (Zingiber zerumbet) rhizomes, a herbal medicine using by Kutai sub- ethnic, eastern of Kalimantan, Indonesia. Human Journals, 6(3), 319-324.

Nag, A., Bandyopadhyay, M., \& Mukherjee, A. (2013). Antioxidant activities and cytotoxicity of Zingiber zerumbet (L.) Smith rhizome. Journal of Pharmacognosy and Phytochemistry, 2(3), 102-108. 
Norfazlina, M., Zuraina, M. . F., N.F, R., Nazip, S. M., Rumiza, A. ., Zaila, C. S., Florinsiah, L. (2013). Cytotoxicity study of Nigella sativa and Zingiber zerumbet extracts, thymoquinone and zerumbone isolated on human myeloid leukemia (HL60) cell. The Open Conference Proceedings Journal, 4, 99-107.

Plaza, M., Amigo-Benavent, M., del Castillo, M. D., Ibáñez, E., \& Herrero, M. (2010). Neoformation of antioxidants in glycation model systems treated under subcritical water extraction conditions. Food Research International, 43(4), 1123-1129.

Plaza, M., \& Turner, C. (2015). Pressurized hot water extraction of bioactives. Trends in Analytical Chemistry, 71, 39-54.

Rumiza, A. R., \& Pihie, A. H. L. (2005). The antiprofilerative effect of Zingiber zerumbet extracts fractions on the growth of human breast carcinoma call lines. Malaysian Journal of Pharmaceutial Sciences, 3(1) 45-52.

Sakinah, S. A. S., Handayani, S. T., \& Hawariah, L. P. A. (2007). Zerumbone induced apoptosis in liver cancer cells via modulation of $\mathrm{Bax} / \mathrm{Bcl}-2$ ratio. Cancer Cell International, 7(4), 1-11.

Sarip, M. S. M., Morad, N. A., Ali, N. A. M., Yusof, Y. A. M., \& Yunus, M. A. C. (2014). The kinetics of extraction of the medicinal ginger bioactive compounds using hot compressed water. Separation and Purification Technology, 124, 141-147.
Silva, E. M., Rogez, H., \& Larondelle, Y. (2007). Optimization of extraction of phenolics from Inga edulis leaves using response surface methodology. Separation and Purification Technology, 55(3), 381-387.

Snyder, L. R., Kirkland, J. J. \& Glajch, J. L. (2012). Practical HPLC method development. Wiley Interscience: New York, pp.1-14.

Teo, C. C., Tan, S. N., Yong, J. W. H., Hew, C. S., \& Ong, E. S. (2010). Pressurized hot water extraction (PHWE). Journal of Chromatography A, 1217(16), 2484-2494.

Yodkeeree, S., Sung, B., Limtrakul, P., \& Aggarwal, B. B. (2009). Zerumbone enhances TRAIL-induced apoptosis through the induction of death receptors in human colon cancer cells: Evidence for an essential role of reactive oxygen species. Cancer Research, 69(16), 6581-6589.

Zakaria, Z. A., Mohamad, A. S., Chear, C. T., Wong, Y. Y., Israf, D. A., \& Sulaiman, M. R. (2010). Antiinflammatory and antinociceptive activities of Zingiber zerumbet methanol extract in experimental model systems. Medical Principles and Practice, 19(4), 287-294.

Zakaria, Z. A., Yob, N. J., Jofrry, S. M., Affandi, M. M. R. M. M., Teh, L. K. \& Salleh, M. Z. (2011). Zingiber zerumbet (L.) Smith: A review of its ethnomedicinal, chemical, and pharmacological uses. Evidence-Based Complementary and Alternative Medicine, 2011. 